\title{
Using Fine Recycled Concrete Aggregate for Mortar Production
}

\author{
Catarina Neno $^{\mathrm{a}}$, Jorge de Brito ${ }^{\mathrm{a} *}$, Rosário Veiga ${ }^{\mathrm{b}}$ \\ a'DECivil-IST, Technical University of Lisbon, Av. Rovisco Pais, 1049-001, Lisbon, Portugal \\ ${ }^{\mathrm{b}}$ Department of Buildings, National Laboratory of Civil Engineering - LNEC, \\ Av. do Brasil, 101, 1700-066, Lisbon, Portugal
}

Received: February 11, 2013; Revised: September 4, 2013

\begin{abstract}
This research assessed the performance of mortars in which recycled concrete aggregates (RCA) was a component. It replaced natural sand but kept the same particle size distribution. Three mortars were produced with replacement ratios of $20 \%, 50 \%$ and $100 \%$ as well as a reference mortar containing no recycled aggregate. The compressive and flexural strength, water absorption by capillarity, drying capacity and susceptibility to cracking of these mortars were analyzed first. Then, based on these results, the most satisfactory replacement ratio was chosen and the following properties were analyzed: water retentivity, shrinkage, adhesive strength, modulus of elasticity, and water vapor permeability. Somewhat surprisingly the best results in the first stage occurred for $20 \%$ and $100 \%$ replacement ratios, leading to a cautious choice of the $20 \%$ ratio for the second stage. Generally the mortar with $20 \%$ replacement ratio performed better than the reference mortar, except for adhesive strength and dimensional stability.
\end{abstract}

Keywords: concrete waste, recycled aggregates, coating mortars, performance

\section{Introduction}

World population expansion has led to an exponential increase in the consumption of natural resources and energy, and the amount of waste produced. Until quite recently, and despite years of experience in the field, the construction industry has seemed quite oblivious to worries about managing the waste produced.

Construction is not only one of greatest generators of waste; it also consumes around $40 \%$ of all extracted natural resources ${ }^{1}$. It is thus essential to intervene to encourage more sustainable construction practices.

Studies on the use of recycled aggregates have mostly focused on their coarse fraction and ignored the fine fraction. This is basically because the extreme porosity of fine recycled materials leads to reductions in the performance of any composites containing them ${ }^{2}$.

Our study focused on the viability of replacing sand with fine recycled concrete aggregate in the production of mortar, i.e. composites made of cement, fine aggregates, water and eventually admixtures and additions, particularly for use as wall coatings and mixed on site for immediate application.

This research intends to contribute to the management and reuse of construction and demolition waste (CDW) in order to reduce their impact, and simultaneously reducing the extraction of sand from river beds, an activity with a great potential for degrad-ing the environment.

The most important characteristics of hardened mortar for wall covering are: mechanical strength, modulus of elasticity, water permeability, adhesive strength and resistance to weathering, and those of fresh mortar are workability, and water retentivity ${ }^{3}$. Several mortars with recycled aggregates are assessed based on

*e-mail: jb@ civil.ist.utl.pt these characteristics and by comparison with a reference conventional mortar, in order to verify their performance as renderings.

\section{Literature Review}

Various studies on the use of recycled aggregate in concrete have been performed in the last few years, but for mortar such research is only just starting. Some interesting conclusions have nevertheless been reached.

It was generally found that mortars containing recycled aggregates need more mixing water to reach the same level of workability as conventional mortars because of the greater porosity of the recycled aggregates. It is well established that aggregates with greater porosity and surface area per volume unit absorb more water and therefore they make the resulting mortar more consistent ${ }^{3}$. Bavaresco ${ }^{4}$ observed that mortars made with recycled aggregate consumed $75 \%$ more water than that made with sand. Miranda ${ }^{5}$ and Silva et al. ${ }^{6}$ obtained similar results, i.e. more mixing water needed for modified mortars in order to obtain a satisfactory workability. However, because the high water absorption of these porous aggregates the effective content in the cement paste can be substantially lower than the total water content, a distinction has to be drawn between total and effective w/c ratio in mortars containing recycled aggregate ${ }^{7}$.

The mortar's density is also affected. According to the literature there is a downward trend as recycled aggregates are incorporated into the mix because their particle density is lower than that of conventional aggregates. In the Hanžič et al. ${ }^{3}$ study the dry bulk density of the hardened mortars containing recycled aggregate was $8 \%$ lower than that of mortar made with natural sand only, and a similar 
situation occurred in the Silva et al. ${ }^{6}$, Bavaresco $^{4}$ and Pedrozo ${ }^{8}$ studies.

Most studies consulted found that water retentivity of fresh mortar made with recycled aggregates was lower. Since they are made of porous materials (ceramic materials and crushed concrete) water retention capacity becomes an important characteristic ${ }^{9}$. In the Hamassaki et al. ${ }^{10}$ study the mortar with the highest water retentivity was the one containing ceramic bricks and the mortars made with concrete waste had a lower retentivity than the reference mix. This situation is corroborated by Miranda and Selmo ${ }^{11}$ and Bavaresco ${ }^{4}$ where the mortars with the highest concrete waste content had lower water retentivity than the one with ceramic material. Therefore it is concluded that a higher content of concrete in the recycled aggregates leads to lower ability to retain the mixing water.

In terms of water absorption by capillary action, results from the studies consulted reveal greater water absorption and porosity, which are both typical of recycled aggregates. In the Silva et al. ${ }^{6}$ and Pedrozo ${ }^{8}$ studies, however, replacing sand with recycled aggregate led to a decrease of $20 \%$ to $30 \%$ in absorption by capillary ac-tion of the mortars made with recycled aggregates.

This better initial performance is explained by the combination of the slight pozzolanic effect of the fine ceramic aggregates incorporated with a filler effect, even though the content of ultrafine particles in the ceramics was only slightly higher than that in sand. However, for higher replacement ratios the overall effect switches to an increase of the capillary absorption approximately proportional to the ratio, probably because the ultrafine particles content exceeds the potential filling effect they allow.

Previous studies showed a poorer performance with respect to dimensional stability. Because recycled aggregates have a relatively high water demand, shrinkage increases as more are added ${ }^{12}$. Mortar shrinkage may depend on factors such as the w/c ratio, cement content, size grading of the sand, and setting time ${ }^{13}$. Thus, shrinkage depends on the aggregates' density, the porosity of the paste adhered to them and their saturation ${ }^{6,14}$. In the Hamassaki et al. ${ }^{10}$ study it was observed that the mortars with the highest drying shrinkage were those with the highest concrete waste content.

There is no consensus in the literature concerning compressive and flexural strength, since some studies led to higher values in mortars with recycled aggregates and vice-versa. Unlike concrete where compressive strength is a decisive factor for its application, the influence of this property on the performance of coatings is weak ${ }^{3}$.

Pedrozo $^{8}$ and Topçu and Senge ${ }^{15}$ found that almost all mixes with recycled aggregates had higher flexural strength than the reference mix, whereas compressive strength tended to decrease.

When the recycled aggregate was crushed concrete both the flexural and compressive strength improved. The particles' shape (sharper edges) has a positive effect on the interface bond between the aggregate and the surrounding cement paste.

Concerning the adherence to the substrate, it was found in all studies cited that the performance of mortars incorporating concrete waste performed better than the reference mix or mortars made with recycled aggregates of a different nature, such as ceramic materials. Moriconi et al. ${ }^{16}$ and Corinaldesi and Moriconi ${ }^{17}$ found that mortars with recycled aggregates exhibited a stronger bond with the substrate (masonry). According to the authors the mortars with recycled aggregates had higher w/c ratios for the same workability as the reference mix. Thus these mortars could more effectively waterproof the brick surface and guarantee a physical blockage and improved bonding.

This is considered very positive since the mechanical performance of a coating mortar depends more on its connection to the substrate than on the compressive or flexural strength of the paste itself ${ }^{16}$.

As for the modulus of elasticity, it is concluded that it is lower in mortars made with ceramic materials than in mortars containing concrete waste and the reference mix. Topçu and Sengel ${ }^{15}$ obtained a maximum value and a minimum value for the modulus of elasticity at $20 \%$ and $90 \%$ replacement ratios, respectively. The author reports that this was due to the porous nature and lower modulus of elasticity of the recycled aggregates than natural sand.

Based on the literature review it can be concluded that the incorporation of recycled aggregates in mortars to replace conventional aggregate (sand) in small ratios (between $10 \%$ and $20 \%$ ) can improve their performance. After that the performance of mortars made with recycled aggregates tends to decline, particularly for ratios over $50 \%$. Silva et al. ${ }^{6}$ concluded that the optimal replacement percentage in cementitious mortars (for aggregates made of crushed ceramic materials) would be $15 \%$. This difference in performance may also depend on the type of recycled aggregate used, and in the studies performed so far mortars with recycled ceramic aggregates gave better results than those with concrete waste, as in the studies of Levy ${ }^{18,19}$ and Bavaresco ${ }^{4}$, in which the authors compared mortars that incorporated various types of recycled aggregates.

As a conclusion from previous works, it seems to be possible to use recycled aggregates in mortars without loss of performance, but the limitations of use and the optimal content to be adopted depend on the nature of the recycled material. Thus complete studies are needed for each type.

\section{Sequence of Testing}

\subsection{Materials used}

This research was divided into two experimental stages to determine how replacing sand with fine recycled concrete aggregates, in various percentages but with the same particle size distribution, influences mortar's performance.

The two series of tests comprised:

- $1^{\text {st }}$ stage - the characteristics of each mortar mix were compared through a set of relevant tests to find the best replacement ratio to be analyzed in the second stage;

- $2^{\text {nd }}$ stage - complementary tests on the mortar mix selected in the first stage to characterize its performance more precisely and establish the viability of using it in coating solutions. 


\section{Material}

The materials used to make the mortars under study comprise a binder (Portland cement type CEM II/B-L Class $32.5 \mathrm{~N}$ ), two aggregates (river Tagus sand and crushed concrete waste) and tap water.

The concrete waste used was obtained from crushing concrete blocks (class C30/37) until fine aggregate was obtained. The blocks were crushed mechanically using a jaw crusher in the Construction Laboratory in the Civil Engineering and Architecture Department of Instituto Superior Técnico (IST), Lisbon, Portugal. Only the fraction below $4 \mathrm{~mm}$ of the recycled aggregates was used.

Four mortar types were defined, maintaining the size grading of natural sand and changing only the ratio of concrete waste, as seen in Table 1. It was important to keep the particle size distribution constant since the goal was to identify the influence of the recycled aggregate on the mix, and the size distribution of the aggregate (usually sand) can influence the characteristics of the fresh and hardened $\operatorname{mortar}^{13}$.

To that effect, the recycled concrete aggregates (RCA) were sieved before mixing. However, the finer sieve used was the \#100 $(0.149 \mathrm{~mm})$ and therefore all the sand and RCA material passing through that sieve (19.6\%) was not separated in the finer fractions. The percentage of material passing the $0.063 \mathrm{~mm}$ sieve was completely different in the sand $(0.64 \%)$ and the RCA $(10.49 \%)$, which proved to have some influence on the results as seen below.

\section{Methods, Results and Discussion}

\subsection{First stage}

This first selective stage included identification tests of the mortars' components and characterization and performance tests of the fresh and hardened mortars.

CRA revealed much higher water absorption than NA. CRCA had a value of $8.49 \%$ and CRMMA $16.34 \%$, which is explained by the higher absorption capacity of the hardened paste adhered to the CNA as well as by the rougher surface of the CRA. As for the crushed ceramic aggregates, their high porosity is well known and their elongated shape further enhances their water absorption capacity.

\subsubsection{Consistency of fresh mortar}

The test was performed according to European standard EN 1015-3 $3^{[20]}$. According to standard EN 1015-2 ${ }^{[21]}$ the consistency of coating mortars with bulk density over $1200 \mathrm{~kg} / \mathrm{m}^{3}$ should be $175 \mathrm{~mm} \pm 10 \mathrm{~mm}$, and this was the criterion used to define the mixing water content.

The results presented in Table 2 agree with the literature, e.g. the Bavaresco ${ }^{4}$ study, where the mortars containing concrete aggregates needed more water during mixing than conventional mortars, for equivalent consistency.

With the incorporation of RCA, the water content of the mixes with RCA (A20, A50 and A100) increased but did not show a clear trend. Even though the objective was to replace the sand particles with recycled waste particles of exactly the same size, in the last sieve (smaller than $0.149 \mathrm{~mm}$ ) there was no lower limit on particle size and therefore very fine concrete particles must have been retained, unlike in sand. These very fine particles of RCA eventually led to a filler effect and improved the mix's workability. However, the trend was not consistent for the whole replacement ratio range.

\subsubsection{Bulk density of fresh mortar}

This test was performed according to European standard EN 1015-6 $6^{[22]}$ using two samples per mix type.

Figure 1 shows that the fresh bulk density decreases linearly as the content of concrete waste increases. This can be explained by the substantially lower particle density of the concrete waste (varying from $842 \mathrm{~kg} / \mathrm{dm}^{3}$ for the under $0.149 \mathrm{~mm}$ fraction to $1069 \mathrm{~kg} / \mathrm{dm}^{3}$ for the $2.38-4.76 \mathrm{~mm}$ fraction) compared with that of sand $\left(1433 \mathrm{~kg} / \mathrm{dm}^{3}\right)$ and also the increased water content. This corroborates previous studies in all of which the mortars with RCA had lower fresh bulk density than the reference mix.

\subsubsection{Dry bulk density of hardened mortar}

This test was performed in accordance with European standard EN 1015-10 $0^{[23]}$ using prismatic samples $(40 \mathrm{~mm} \times 40 \mathrm{~mm} \times 160 \mathrm{~mm})$ that were later tested for flexural and compressive strength. Three specimens per mix type were measured after curing for 28 days.

The results are shown in Figure 2 and demonstrate that the hardened mortars' dry bulk density again have a downward linear trend after A20.

Table 1. Composition of the mortars and w/c relation.

\begin{tabular}{ccc}
\hline \% of replacement & Volumetric proportion & w/c \\
\hline 0 & $1: 4$ & 1.21 \\
20 & $1: 4$ & 1.31 \\
50 & $1: 4$ & 1.30 \\
100 & $1: 4$ & 1.27 \\
\hline
\end{tabular}

Table 2. Mixing water needed to achieve the target workability and respective results of the consistency test.

\begin{tabular}{ccc}
\hline Mortar & Mixing water $\left(\mathbf{m l} / \mathbf{d m}^{3}\right)$ & Consistency $(\mathbf{m m})$ \\
\hline A0 & 313.3 & 176 \\
A20 & 340.0 & 170 \\
A50 & 336.7 & 178 \\
A100 & 330.0 & 170 \\
\hline
\end{tabular}

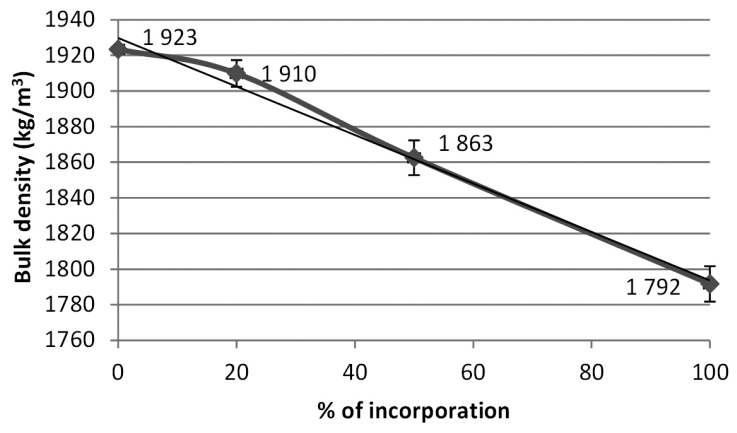

Figure 1. Bulk density of fresh mortar relative to replacement ratio. 
The reason is the same as for the decrease of the fresh bulk density. The small initial increase is linked to a possible reduction of the voids due to the probable filler effect stated in the Materials section concerning especially the fraction below $0.063 \mathrm{~mm}$ (thus increasing the mass for the same volume). This filler effect no longer prevails after the $20 \%$ replacement ratio because the volume of concrete waste increases and the influence of its lower particle density becomes more significant than the filler effect of the ultrafine fraction.

\subsubsection{Flexural and compressive strength of hardened mortar}

These tests were performed according to European standard EN 1015-11 $1^{[24]}$ to determine the strength of the mortars under a uniform compressive and flexural stress. This is achieved by submitting the specimen to a flexural test and then applying a compressive load to each half specimen that leads to its failure. Ultimate loads are registered for both tests. The flexural test was performed on three prismatic specimens $(40 \mathrm{~mm} \times 40 \mathrm{~mm} \times 160 \mathrm{~mm})$ per mix after curing for 28 days. The compressive test was carried out on the six resulting half specimens.

Figures 3 and 4 indicate that there is a similar pattern in flexure and compression. The respective strengths show a growing trend until $20 \%$ replacement, a slight decrease for $50 \%$ and reach a new maximum for $100 \%$.

This may be caused by various factors. The concrete particles have a higher specific surface and are sharperedged and more porous than sand, so the bond with the

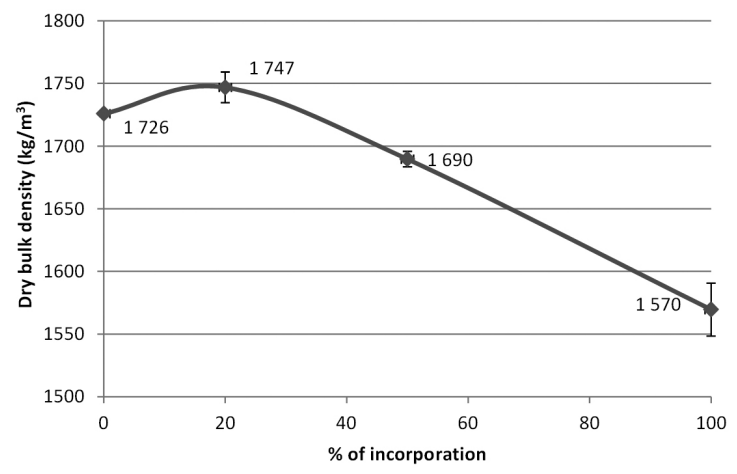

Figure 2. Dry bulk density of hardened mortar relative to replacement ratio.

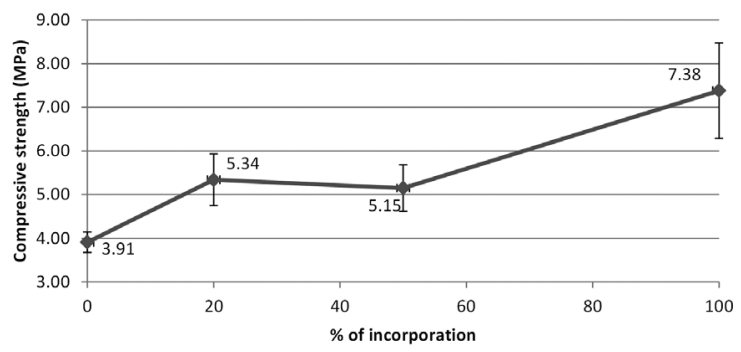

Figure 3. Compressive strength of hardened mortar relative to replacement ratio. cement paste of the mix is better. Furthermore, this waste may contain some non-hydrated cement that completes its hydraulic reactions and sets when in contact with water, leading to greater cohesion between the particles and strength $^{25}$.

Of those made with RCA the mortar with $100 \%$ has the lowest water content in its composition, i.e. for the same cement it has less water and lower voids volume, creating greater cohesion and higher strength in the mortar. Usually the addition of air (porosity) leads to a reduction of around $3 \%$ to $5 \%$ in mechanical strength per $1 \%$ of air incorporated ${ }^{26}$.

These results agree with those of other authors such as Hamassaki et al. ${ }^{10}$, who obtained the best compressive strength results for the mix with $100 \%$ incorporation of concrete waste.

Other studies report that the compressive strength decreased in the mortars with recycled aggregates, for example Pedrozo ${ }^{8}$ used a volumetric proportion of $1: 3$ (cement: sand) and the recycled aggregates were of various types, thus decreasing the bond between particles.

As for flexural strength, the results agree with previous studies, especially the one by $\mathrm{Pedrozo}^{8}$, in which the maximum flexural strength was obtained in the mortar containing $100 \%$ recycled aggregates. Even though the reference mix of the Corinaldesi and Moriconi ${ }^{17}$ study had higher strength than those containing recycled aggregates made of bricks or a recycled aggregates mixture, the mix with concrete waste was the strongest at 28 days.

In the Topçu and Senge ${ }^{15}$ study where crushed tiles were incorporated the reference mix had the lowest figures for flexural strength while the maximum strength was achieved for a recycled aggregates replacement ratio of $30 \%$.

\subsubsection{Water absorption due to capillary action of hardened mortar}

To determine the water absorption due to capillary action the methodology and procedures set out in European standard EN $1015-18^{[27]}$ were followed. What was measured is the increase in water mass that ascends by capillarity through the prismatic specimen cross-section in contact with a water surface. The test was performed on three specimens (semi-prisms) per mix type after curing for 28 days. The water absorption coefficient due to capillary action was

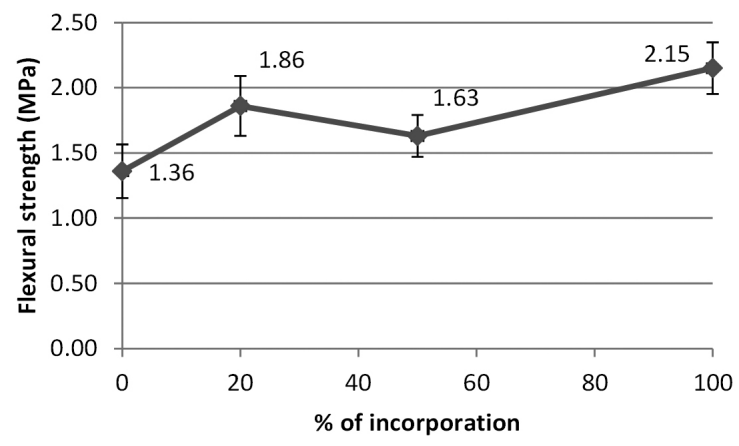

Figure 4. Flexural strength of hardened mortar relative to replacement ratio. 
determined and the water absorption rate expressed over a period of between 10 and $90 \mathrm{~min}$.

In this test the mortars showed almost constant initial water absorption coefficient values that decreased after a $50 \%$ replacement ratio (Figure 6). The mortar with the highest capillarity coefficient was the reference mix (A0) and the one with the lowest was A100 (Figure 6), though it was also the one that absorbed most water at long term (Figure 5). This means that the open porosity of A100 is the highest, confirming the results of the other tests, so the asymptotic water absorption is also the most significant; on the other hand, the average pores' diameter is possibly the lowest, due to best connection between matrix and aggregates and probably also due to the filler effect, explaining the lowest capillary rate expressed by the coefficient of capillarity ${ }^{28}$.

Given that the recycled aggregates are more porous than natural sand they can absorb more water that later on can combine with cement leading to a positive effect on the mortar's hydration process ${ }^{3}$.

Another relevant factor is the fact that the mortar with $100 \%$ RCA is the one using least water in its composition (of those made with RCA). The amount of free water in the mix and the voids volume are thus reduced for this mortar, which increases the cohesion between particles and decreases the water absorption rate by capillarity (Figure 5).

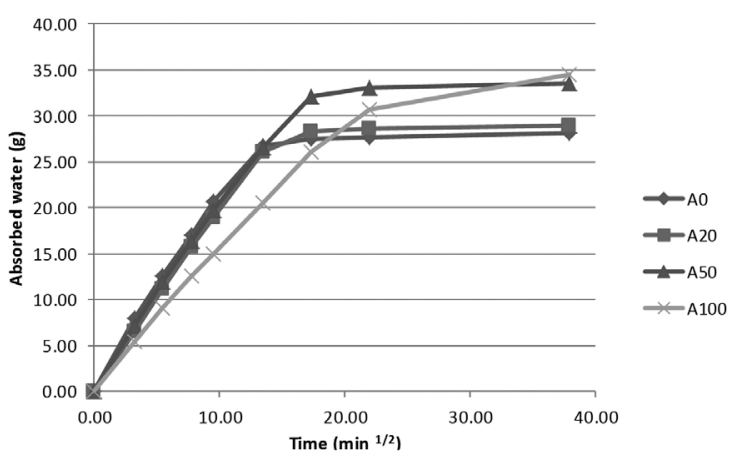

Figure 5. Water absorption by capillarity action tests results of hardened mortar relative to replacement ratio.

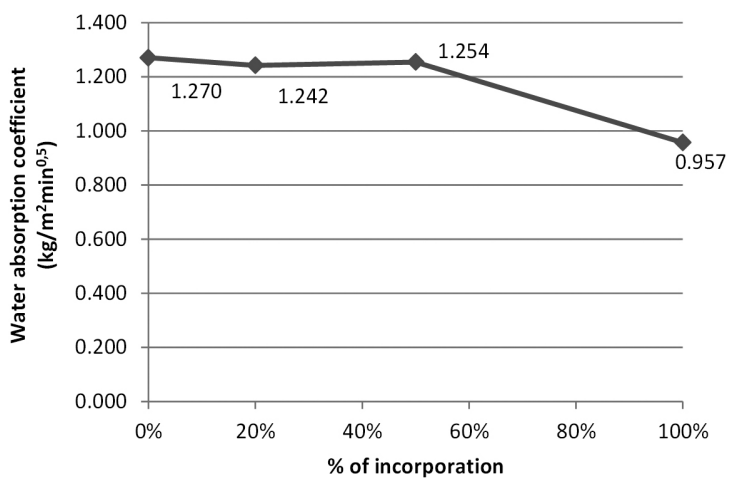

Figure 6. Water absorption coefficient by capillary action of hardened mortar relative to replacement ratio.
Previous findings do not totally agree with these results. Pedrozo $^{8}$ also obtained an increase in capillary absorption as the incorporation rate of recycled aggregate went up, again because of the nature of the recycled materials (various types of recycled aggregates) that created more voids and less uniformity and cohesion in the mortar.

\subsubsection{Drying test of hardened mortar}

To determine the drying capacity the three specimens used in the water absorption by capillary action test were removed from the water containers and left to dry at the same temperature. They were then weighed 30, 60, 90, 270 and $450 \mathrm{~min}$ after the first weighing and again at $24 \mathrm{~h}$ intervals until constant mass.

The results are presented in Figure 7.

It was found that the mortars containing concrete waste $(20 \%, 50 \%$ and $100 \%)$ exhibited behavior relatively similar to that of the reference mix $(0 \%)$. The highest water evaporation rate for all mixes occurred between 400 and $3600 \mathrm{~min}(6.7 \mathrm{~h}$ to $60 \mathrm{~h})$.

\subsubsection{Susceptibility to cracking}

This characteristic was qualitatively evaluated by applying each mortar type to three bricks. The surface was then checked at intervals during 28 days curing in a dry conditioned room $\left(23^{\circ} \mathrm{C} / 50 \% \mathrm{RH}\right)$.

None of the mortars showed any type of cracking (see Figure 8) after 7 months of observation. It is thus concluded that none of the replacement ratios tested is very susceptible to cracking and therefore concrete waste used as fine aggregate in mortars did not significantly worsen their short/medium-term performance in terms of cracking. However, this application on relatively limited areas such as a brick's surface is no guarantee that there is no cracking in larger areas and therefore this test is but a first approach to this analysis.

\subsubsection{Selection of mortars for the second stage}

Analyzing and comparing the results from the first stage for the three mortars with RCA (A20, A50 and A100) the one with most consistent and satisfactory results was chosen.

Mortar A100 had better results than the others and would be the probable choice for the second stage. However it was not chosen because the initial purpose of this mix was to

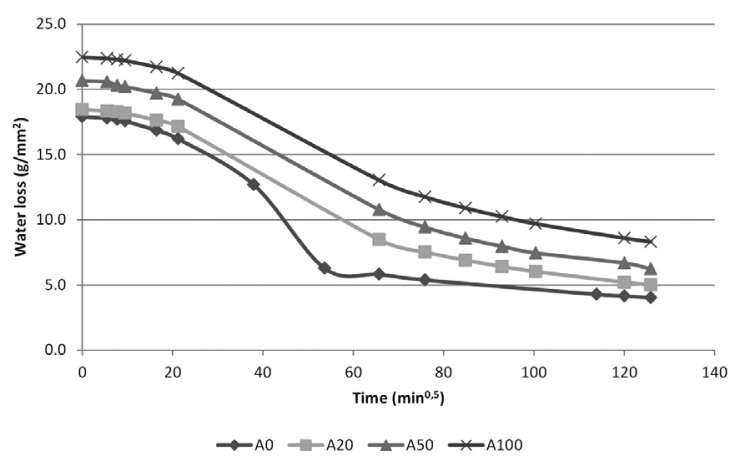

Figure 7. Specimens' water loss by evaporation relative to square root of time. 
quantify the asymptotic trend of the results (which was not achieved) and to check how the mortars would perform in a limit situation, i.e. total replacement of sand with recycled aggregate. It was decided to be conservative and choose mortar A20 for which every property studied improved relative to the reference mix, particularly compressive and flexural strength where the results were better for A20 than A50. Even though A100 returned even higher figures for these properties they were not particularly advantageous since a coating mortar needs minimal strength and some elasticity in order to cope with the substrate movements without cracking. This cautious appraisal of the situation proved to be the most appropriate in the second stage.

In terms of capillary water absorption, mortar A20 has a lower coefficient than A50 and A0, i.e. the mortar's performance improved from this point of view, but the best result was again given by A100.

In the drying test and the susceptibility to cracking test no differences were detected between the three mortars.

Other important properties of the mortars were tested in the second stage and these results allowed a better general characterization of the advantages and drawbacks of the mortar with $20 \%$ incorporation of concrete waste compared with the reference mix.

\subsection{Second stage}

\subsubsection{Dimensional stability (shrinkage)}

This test was performed according to Cahier 2669-4 ${ }^{[29]}$ on three specimens per mix type (A20 and A0), immediately after demolding. The shrinkage that occurs while the mortar hardens and in the first months of curing may be called drying shrinkage ${ }^{13}$.

Figure 9 shows that the dimensional change results for the reference mortar $(\mathrm{A} 0)$ are substantially less pronounced than those of mortar made with RCA (A20). It is thus concluded that the mortar containing concrete waste shrinks considerably more than the reference one, in accordance with Kikuchi et al. ${ }^{12}$.

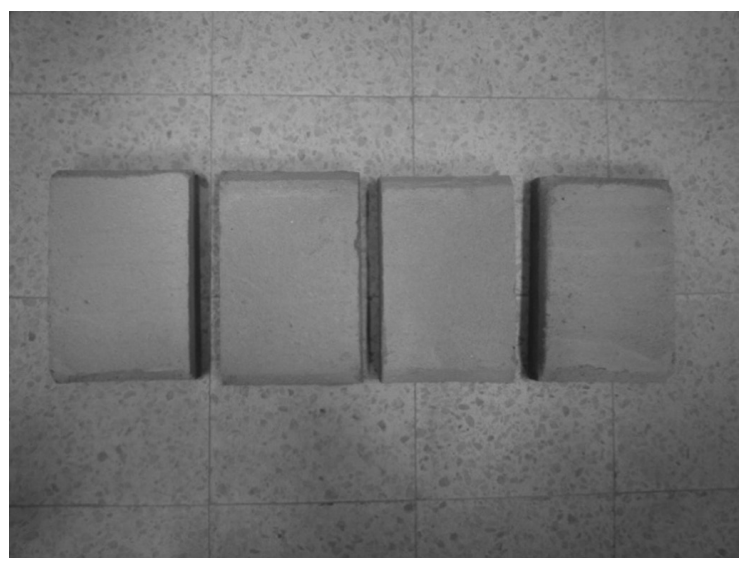

Figure 8. Results from cracking susceptibility test.
This increase in dimensional variability may be because recycled aggregates such as concrete waste are made of much more absorbent and porous particles than natural sand, leading to a reduction in stiffness that prevails over the filler effect advantage.

This phenomenon is also associated with the higher cement (and cement paste) content, possibly incompletely stabilized, and very fine particles in the mortar made with concrete waste $)^{13}$, which would both lead to increased shrinkage.

\subsubsection{Water retentivity of fresh mortar}

This test was performed according to European standard prEN $1015-8^{[30]}$ and is based on the evaluation of the water retained through a suction procedure, thus determining the amount of water retained within the mortar after the procedure is over. The result is presented as a percentage of the water initially retained within the mortar and is the average of three specimens per mix type.

The results presented (Table 3) show that the mortar containing concrete waste (A20) has greater water retentivity than the reference mortar (A0). This is a very positive result because the more water the mortar retains the more probable the hydration of the cement within the mix is, which encourages the proper hardening of the paste and improved mechanical strength and adherence ${ }^{31}$.

Cement hydration is a time-consuming process that tends to slow down, but it occurs as long as the mix contains enough water and the temperature range is favorable ${ }^{25}$. Once the water is lost hydration ceases and therefore, according to Silva et al. ${ }^{6}$, water retention helps prevent rapid suction from the substrate and evaporation, which both dries out the mortar and hinders complete hydration of the cement, and so the function of part of the cement switches from binder to filler.

According to Scherer $^{32}$ the existence of different capillary pressures within the mortar during curing may lead to cracking.

These results disagree with some of the previous studies of mortars with recycled concrete aggregates, in particular

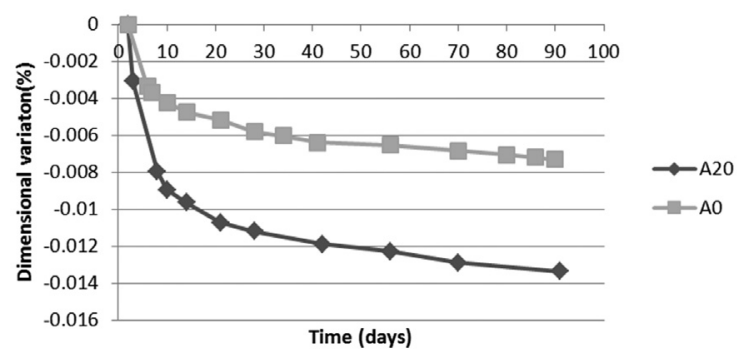

Figure 9. Dimensional instability (shrinkage) of the mortars of the second stage.

Table 3. Results of the water retentivity test.

\begin{tabular}{ccc}
\hline Mortar & Water retentivity (\%) & Standard deviation (\%) \\
\hline A0 & 63.81 & 0.032 \\
A20 & 89.26 & 0.022 \\
\hline
\end{tabular}


by Miranda and Selmo ${ }^{11}$ and Bavaresco ${ }^{4}$. But increased water retentivity was found in studies of mortars containing recycled ceramic aggregates (e.g. the Silva et al. ${ }^{6}$ study found that the mortar with brick waste incorporation had the best water retentivity). In the Hanžič et al. ${ }^{3}$ study the mortars with recycled aggregates also gave the best results in terms of water retention capacity.

\subsubsection{Adhesive strength of hardened mortar}

This test was performed according to European standard EN 1015-12 $2^{[33]}$ and consisted of determining the tensile force necessary (adhesive strength) to pull off a given area of mortar applied to a substrate. The test was performed on three specimens per mix type after curing for 28 days.

Table 4 shows that the adhesive strength of the mortar made with RCA (A20) is lower than that of the reference mix (A0). But the difference is small, given the dispersion of the results (high standard deviations). The scatter in the results of this test is explained by its execution, which depends on various factors such as procedures to humidify the brick (substrate), the manual application of the mortar on the brick, and the way the manual pull-off equipment is handled. Groot ${ }^{34}$ concluded that the two water flows can influence the mortars' adhesive strength: from the mortar to the brick (right after they are in contact) and from the brick to the mortar (after compaction and initial hydration of the paste).

Therefore it can be considered that the mixes showed a similar performance without significant differences.

\subsubsection{Modulus of elasticity of hardened mortar}

This test was performed according to the standard NP EN $14146^{[35]}$ and it consisted of using a fundamental frequencies measuring device to determine the resonance frequency of a prismatic specimen subjected to longitudinal vibrations. The dynamic modulus of elasticity depends on

Table 4. Results of the adhesive strength test.

\begin{tabular}{cccc}
\hline Mortar & $\begin{array}{c}\text { Adhesive strength } \\
\text { (MPa) }\end{array}$ & $\begin{array}{c}\text { Standard deviation } \\
\text { (MPa) }\end{array}$ & $\begin{array}{c}\text { Type of } \\
\text { failure }\end{array}$ \\
\hline A0 & 0.33 & 0.113 & $\begin{array}{c}\text { Adhesive } \\
\text { Adhesive/ } \\
\text { cohesive }\end{array}$ \\
\hline
\end{tabular}

Table 5. Results of the determination of the module of elasticity.

\begin{tabular}{ccc}
\hline Mortar & $\begin{array}{c}\text { Module of elasticity } \\
(\mathbf{G P a})\end{array}$ & $\begin{array}{c}\text { Standard deviation } \\
(\mathbf{G P a})\end{array}$ \\
\hline A0 & 7.07 & 0.46 \\
A20 & 8.25 & 0.38 \\
\hline
\end{tabular}

this value. The test was performed on three specimens per mix type after curing for 28 days.

Table 5 shows that the modulus of elasticity of the mortar with concrete waste incorporation (A20) is slightly higher than that of the reference mortar (A0). This increase is not necessarily favorable because the modulus of elasticity is directly related to the cracking propensity of mortars, since deformations give rise to higher internal stresses. These results concur with those for compressive and flexural strength, which were also higher in the mortar made with recycled aggregates.

This trend is partly due to the greater dry bulk density (higher density and lower voids content) of the mortar with concrete waste, which is linked to the filler effect mentioned above that seems to prevail for this replacement ratio (20\%).

The results of previous studies, particularly those by Silva et al. ${ }^{6}$ and Topçu and Sengel ${ }^{15}$, did not agree with the current investigation. This may be because their recycled aggregates came from more porous ceramic materials with higher voids content, which implies slower propagation velocity of the ultrasonic waves and thus a lower modulus of elasticity ${ }^{36}$.

\subsubsection{Water vapor permeability of hardened mortar}

This test was performed according to European standard EN 1015-19 ${ }^{[37]}$ and was based on inducing different pressure levels in two opposing faces of a $20 \mathrm{~mm}$ circular specimen and measuring the amount of water vapor that circulates between them. The test was performed on five specimens per mix type after curing for 28 days. Water vapor permeability is a factor in pathology associated with excess condensation or dampness, usually linked with lack of permeability ${ }^{26}$.

The results in Table 6 show that the water vapor permeability of the mortar containing concrete waste (A20) is slightly higher than that of the reference mix (A0). This is again linked to the concrete waste particles being more porous and having higher water absorption, thus allowing freer permeability for water vapor to circulate. However, the difference is small because the influence of particle porosity was to some extent offset by a filler effect that hinders water vapor circulation.

With these results it is concluded that the mortar with RCA incorporation has a slightly improved performance in terms of capacity to release water vapor by comparison with conventional mortars, because it facilitates drying of both the mortar and its substrate.

\subsubsection{Render cracking susceptibility - restrained shrinkage and tensile strength of hardened mortar}

This test is based on a technique developed and validated by Veiga $^{38}$ at the laboratory of wall coatings of LNEC

Table 6. Results of the water vapor permeability test.

\begin{tabular}{cccc}
\hline Mortar & Permeability (ng/(m.s.Pa)) & Standard deviation $(\mathbf{n g} /(\mathbf{m} . \mathbf{s . P a}))$ & $\begin{array}{c}\text { Thickness of the diffusion air layer } \\
\text { equivalent to } \mathbf{~ c m ~ o f ~ m o r t a r ~}(\mathbf{m})\end{array}$ \\
\hline A0 & 23.9 & 0.021 & 0.15 \\
A20 & $25.2 \mathrm{v}$ & 0.012 & 0.15 \\
\hline
\end{tabular}


Table 7. Results from the cracking susceptibility test.

\begin{tabular}{ccccccc}
\hline Mortar & Maximal force $\mathbf{F m}(\mathbf{N})$ & Tensile resistance $\operatorname{Tr}(\mathbf{N})$ & $\mathbf{G}$ & $\mathbf{S}$ & $\mathbf{R}(\mathbf{m m})$ & Class \\
\hline A0 & 68.55 & 100.43 & 71.3 & 1.47 & 1.04 & Low \\
A20 & 89.52 & 168.30 & 70.7 & 1.88 & 0.79 & Moderate \\
\hline
\end{tabular}

Table 8. Classification of cracking susceptibility based on coefficients $S / R^{41,42}$.

\begin{tabular}{lcc}
\multicolumn{1}{c}{ Class } & S & R \\
\hline Low cracking susceptibility & $\mathrm{S} \geq 1$ & $\mathrm{R} \geq 1$ \\
Moderate cracking susceptibility & $\mathrm{S} \geq 1$ & $0.6 \leq \mathrm{R}<1$ \\
High cracking susceptibility & $\mathrm{S}<1$ & $\mathrm{R}<0.6$ \\
\hline
\end{tabular}

S - Safety coefficient to the opening of the first crack: $S=T r / F m ; R$ - Resistance coefficient to cracking evolution: $R=G / F m$.

Table 9. Functional demands of mortar in current buildings and characteristics of the mortars to be used (adapted from) ${ }^{44}$.

\begin{tabular}{|c|c|c|c|c|}
\hline $\begin{array}{l}\text { Functional } \\
\text { requirement }\end{array}$ & Characteristic & $\begin{array}{l}\text { Requirement or } \\
\text { recommendation }\end{array}$ & $\begin{array}{c}\text { Results for the mortar with } \\
\text { RCA }\end{array}$ & $\begin{array}{l}\text { Requirement } \\
\text { basis }\end{array}$ \\
\hline \multirow{3}{*}{$\begin{array}{l}\text { Susceptibility to } \\
\text { cracking }\end{array}$} & Modulus of elasticity & $\mathrm{E} \leq 10000 \mathrm{MPa}$ & $8250 \mathrm{MPa}$ & \multirow{5}{*}{$\begin{array}{l}\text { LNEC's } \\
\text { - Complementary } \\
\text { requirements }\end{array}$} \\
\hline & Restrained shrinkage & $\begin{array}{l}\text { Medium to weak } \\
\text { susceptibility }\end{array}$ & Moderate & \\
\hline & Water retentivity & $\begin{array}{c}\text { No demand } \\
\text { (preferably high) }\end{array}$ & Higher than the reference mix & \\
\hline $\begin{array}{l}\text { Water vapor } \\
\text { permeability }\end{array}$ & $\begin{array}{l}\text { Thickness of the air diffusion layer } \\
\text { equivalent to } 0.10 \mathrm{~m} \text { of mortar } \mathrm{Sd}(\mathrm{m})\end{array}$ & $\mathrm{Sd} \leq 0.15 \mathrm{~m}$ & $\mathrm{Sd}=0.15$ & \\
\hline $\begin{array}{c}\text { Adherence to the } \\
\text { substrate }\end{array}$ & Pull-off & $\begin{array}{c}\geq 0.3 \mathrm{MPa} \text { or } \\
\text { cohesive failure }\end{array}$ & $0.3 \mathrm{MPa}$ & \\
\hline
\end{tabular}

(LNEC-LeRevPa) and is described in test form FE-Pa37 [39] and in several other works ${ }^{40,41}$.

When the mortar is applied to a given substrate the combination of adhesion and dimensional variation induced by shrinkage may lead to high tensile stresses within the $\operatorname{mortar}^{38,40,42}$. If these stresses exceed the mortar's tensile strength cracking usually occurs, which reduces the material's durability.

The test was performed on three specimens per mix type. The stress due to restrained shrinkage was monitored and registered for 7 days after casting, when the tensile test was performed.

Table 7 clearly shows that the mortar specimens made with recycled concrete aggregates (A20) are slightly less able to resist cracking than the reference mix specimens (A0).

The classification of the test (Table 8) indicates that the A20 mortar is more likely to crack than A0. These results confirm those for the modulus of elasticity and of dimensional instability, which both indicated a higher susceptibility to cracking.

Mortar A20 had a higher value of the parameter "S" (safety coefficient to the opening of the first crack - Table 8) than mortar A0, demonstrating higher tensile strength (in agreement with the results of the flexural strength test described above). Failure energy, evaluated by the parameter "R" (resistance coefficient to cracking evolution - Table 8), was slightly lower, which is equivalent to an increase in cracking susceptibility.

\section{Conclusions}

The results obtained allow a better characterization of mortars made with fine recycled concrete aggregates, in both fresh and hardened state.

Concerning the fresh-state properties it is concluded that:

- The total water content in the mortars with $20 \%$ concrete waste incorporation was substantially higher than that in the reference mix, for the same workability;

- As the RCA incorporation ratio increased above $20 \%$ the water content fell, showing that the cement paste gained plasticity; but this effect is not significant;

- In terms of the bulk density of fresh mortar the expected trend was confirmed, i.e. it decreases proportionally with the concrete waste ratio; thus it is concluded that the greater the difference in particle density between the alternative aggregates and the substitution rate of natural aggregates with recycled aggregates the bigger the difference of the fresh mortars in terms of bulk density;

- A $40 \%$ increase in water retentivity of the mortars containing RCA compared with the reference mix denotes an improvement in performance, since this represents a greater probability of the binder hydrating completely and consequently a gain in mechanical and adhesive strength.

As for the hardened-state mortars' properties, the mixes with RCA incorporation registered a very reasonable 
performance compared with the reference mix. All the results presented complied with the criteria proposed by Veiga $^{43}$ (Table 9):

- Concerning water absorption by capillarity, the presence of concrete waste in mortars seems to have a very positive effect since the water absorption rate decreased (by up to $25 \%$ for total replacement versus the reference mix);

- In terms of compressive and flexural strength, incorporating concrete waste in mortars (replacing sand) led to a substantial improvement (35\% in flexural strength and $45 \%$ in compressive strength); as for adhesive strength of the RCA mortar to the substrate there was a decrease (around 20\%) from the reference mix figure, though it remained well within the limits set in Table 9;

- The performance of the mortar with RCA incorporation in terms of water vapor permeability was slightly superior (approximately 5\%) to the reference mix;

- The results for cracking susceptibility were generally a bit poorer than those of the reference mix; besides an increase of around $45 \%$ of shrinkage in the mortar made with RCA, the modulus of elasticity was also higher, which indicates this mortar has a higher propensity to cracking; this slight loss of performance was confirmed in the restrained shrinkage test in which the susceptibility of the RCA mortar to cracking was classified as moderate whereas the reference mix was classed as low; even though these results are unfavorable in relative terms they still

\section{References}

1. Pinheiro MD. Environment and sustainable construction. Amadora: Ambient Institute; 2006. In Portuguese.

2. Evangelista L and De Brito J. Durability performance of concrete made with fine recycled concrete aggregates. Cement and Concrete Composites. 2010; 32(1):9-14. http://dx.doi. org/10.1016/j.cemconcomp.2009.09.005

3. Hanžič H, Mautinger A, Jurič B and Oliveira LAP. Water retention capability of mortars made of recycled aggregate. In: Proceedings of the SB08 World Sustainable Building Conference; 2008; Melbourne. Melbourne; 2008. p. 615-621.

4. Bavaresco CR. Use of recycled rubble for mortars production. [Dissertation]. Florianópolis: Federal University of Santa Catarina; 2001. In Portuguese.

5. Miranda L. Study of the factors that influence cracking of coating mortars with recycled rubble. [Dissertation]. São Paulo: Polytechnic School of the University of São Paulo; 2000. In Portuguese.

6. Silva J, De Brito J and Veiga MR. Recycled red-clay ceramic construction and demolition waste for mortars production. Journal of Materials in Civil Engineering. 2010; 22(3):236-244. http://dx.doi.org/10.1061/(ASCE)0899-1561(2010)22:3(236)

7. Desmyter J, Van Dessel J and Blocksmans S. The use of recycled concrete and masonry aggregates in concrete: improving the quality and purity of the aggregates. In: Proceedings of the International Symposium "Exploiting wastes in concrete"; 1999. University of Dundee; 1999. p. $139-150$. comply with the criteria recommended by Veiga ${ }^{43}$, as seen in Table 9.

Overall, the mortar with incorporated fine recycled concrete aggregate proved to be a viable solution with great potential for use in the construction industry. Its mechanical performance is significantly superior regardless of the replacement ratio, and its permeability is also more favourable. As for susceptibility to cracking, the performance obtained for $20 \%$ substitution is considered acceptable and comparable to that of a conventional cementitious mortar.

Based on the results of this study it is recommended to use RCA partially replacing sand in mortars intended for wall rendering, as long as the replacement ratio is limited to $20 \%$ by volume. The very complete test program allowed evaluating many properties that influence the performance of mortars used for wall covering and that are not analysed in most studies, such as susceptibility to cracking, water vapour permeability and water retentivity. It must be stressed that, based on a smaller program (first stage), $100 \%$ replacement would seem favourable, while a more complete study showed the trend to increase susceptibility to cracking.

However, the performance of these modified mortars needs to be fine-tuned in on site large-scale applications.

\section{Acknowledgements}

The authors are grateful for the support of ICIST Research Centre (Instituto de Engenharia de Estruturas, Território e Construção), IST, Technical University of Lisbon and FCT (Fundação para a Ciência e Tecnologia).

8. Pedrozo R. Influence of the replacement of fine natural aggregate with fine recycled aggregate on the properties of mortars and concrete. Florianópolis: Federal University of Santa Catarina; 2008. In Portuguese.

9. Sebaibi Y, Dheilly RM and Queneudec M. Study of the water-retention capacity of a lime-sand mortar: Influence of physicochemical characteristics of the lime. Cement and Concrete Research. 2003; 33(5):689-696. http://dx.doi. org/10.1016/S0008-8846(02)01038-4

10. Hamassaki LT, Sbrihhi NC and Florindo MC. Use of rubble as aggregate for masonry mortars. In: Proceedings of the Workshop on Recycling and reuse of waste as construction materials; 1997; São Paulo. São Paulo: EPUSP/ANTAC; 1997. p. 107-115. In Portuguese.

11. Miranda L and Selmo S. Evaluation of mortars with recycled rubble by rational content-related procedures. In: Proceedings of the III Brazilian Symposium on mortar technology; 1999; Vitória. 1999. p. 295-307. In Portuguese.

12. Kikuchi M, Miura T, Dosho Y and Narikawa M. Application of re-cycled aggregate concrete for structural concrete. Part 1 - experimental study on the quality of recycled aggregate and recycled aggregate concrete. In: Proceedings of the International symposium: Use of recycled concrete aggregate; 1998. Concrete Technology Unit, University of Dun-dee; 1998. p. 55-68.

13. Reddy B and Gupta A. Influence of sand grading on the characteristics of mortars and soil-cement block masonry. Construction and Building Materials. 2008; 22(8):1614-1623. http://dx.doi.org/10.1016/j.conbuildmat.2007.06.014 
14. Mellman G, Meinhold U and Maultzsch M. Processed concrete rubble for the reuse as aggregates. Thomas Telford: Exploiting wastes in concrete: international seminar, University of Dundee; 1999. p. 171-178.

15. Topçu IB and Sengel S. Properties of concretes produced with waste concrete aggregate. Cement and Concrete Research. 2004; 34(8):1307-1312. http://dx.doi.org/10.1016/j. cemconres.2003.12.019

16. Moriconi G, Corinaldesi V and Antonucci R. Environmentallyfriendly mortars: a way to improve bond between mortar and brick. Materials and Structures. 2003; 36(10):702-708. http:// dx.doi.org/10.1007/BF02479505

17. Corinaldesi V and Moriconi G. Behaviour of cementitious mortars containing different kinds of recycled aggregate. Construction and Building Materials. 2007; 23(1):289-294. http://dx.doi.org/10.1016/j.conbuildmat.2007.12.006

18. Levy $\mathrm{S}$ and Helene P. Recycling of rubble in construction, the political and ecologically correct solution. In: Proceedings of the I Brazilian Symposium on mortars technology; 1995; Goiânia. 1995. p. 315-325. In Portuguese.

19. Levy S. The influence of finely crushed hardened mortars and ceramic waste on the properties of new mortars. In: Proceedings of the II Brazilian Symposium on mortars technology; 1997; Salvador. Salvador; 1997. p. 51-63. In Portuguese.

20. European Committee for Standardization - CEN. EN 1015-3: Methods of test for mortar for masonry - Part 3: Determination of consistence of fresh mortar (by flow table). Brussels: CEN; 1999.

21. European Committee for Standardization - CEN. EN 1015-2: Methods of test for mortar for masonry - Part 2: Bulk sampling of mortars and preparation of test mortars. Brussels: CEN; 1998.

22. European Committee for Standardization - CEN. EN 1015-6: Methods of test for mortar for masonry - Part 6: Determination of bulk density of fresh mortar. Brussels: CEN; 1998.

23. European Committee for Standardization - CEN. EN 1015-10: Methods of test for mortar for masonry - Part 10: Determination of dry bulk density of hardened mortar. Brussels: CEN; 1999.

24. European Committee for Standardization - CEN. EN 1015-11: Methods of test for mortar for masonry - Part 11: Determination of flexural and compressive strength of hardened mortar. Brussels: CEN; 1999.

25. Sajedi $\mathrm{F}$ and Razak HA. Effects of curing regimes and cement fineness on the compressive strength of ordinary Portland cement mortars. Construction and Building Materials. 2011;25(4):2036-2045. http://dx.doi.org/10.1016/j. conbuildmat.2010.11.043

26. Gadea J, Rodríguez A, Campos PL, Garabito J and Caldéron V. "ightweight mortar made with recycled polyurethane foam. Cement and Concrete Composites. 2010; 32(9):672-677. http:// dx.doi.org/10.1016/j.cemconcomp.2010.07.017

27. European Committee for Standardization - CEN. EN 1015-18: Methods of test for mortar for masonry - Part 18: Determination of water absorption coefficient due to capillary action of hardened mortar. Brussels: CEN; 2002.

28. Magalhães AC, Moragues A and Veiga MR. Application of some methods on evaluation of porous systems of wall renderings.
In: Anales VII Congreso Internacional de rehabilitación del patrimonio y edificación; 2004; Lanzarote. 2004. In Portuguese.

29. Centre Scientifique et Technique du Bâtiment. Cahier 26694: Certification CSTB des enduits monocouches d'imperméabilisation - Modalités d'essais. Paris: Centre Scientifique et Technique du Bâtiment; 1993.

30. European Committee for Standardization - CEN. EN 1015-8: Methods of test for mortar for masonry - Part 8: Determination of water retentivity of fresh mortar. Brussels: CEN; 1998.

31. Resende M. Pathology of coating mortars. São Paulo: Polytechnic School of the University of São Paulo; 2001. In Portuguese.

32. Scherer GW. Structure and properties of gels. Cement and Concrete Research. 1999; 29(8):1149-1157. http://dx.doi. org/10.1016/S0008-8846(99)00003-4

33. European Committee for Standardization - CEN. EN 1015-12: Methods of test for mortar for masonry - Part 12: Determination of adhesive strength of hardened rendering and plastering mortars on substrates. Brussels: CEN; 2000.

34. Groot C. Effects of water on mortar-brick bond. [Thesis]. Delft: Technische Universiteit Delft; 1993.

35. European Committee for Standardization - CEN. EN 14146 : Natural stone test methods - Determination of the dynamic modulus of elasticity (by measuring the fundamental resonance frequency). Brussels: CEN; 2004.

36. Silva NG and Campiteli VC. Correlation between dynamic module of elasticity and mechanical strength of cement mortars, lime and sand. Built Environment. 2008; 8(4):21-35.

37. European Committee for Standardization - CEN. EN 1015-19: Methods of test for mortar for masonry - Part 19: Determination of water vapour permeability of hardened rendering and plastering mortars. Brussels: CEN; 1998.

38. Veiga MR. Performance of rendering mortars. Contribution to the study of their cracking resistance. [Thesis]. Porto: Engineering Faculty from Porto University; 1997. In Portuguese.

39. FE Pa. 37: Test of susceptibility to cracking. Lisboa: LNEC; 1998. In Portuguese.

40. Veiga MR. Influence of application conditions on the cracking susceptibility of renderings, RILEM Publications S.A:R.L. Concrete Science and Engineering. 2000; 2:134-140.

41. Veiga MR, Velosa A. Magalhães A. Evaluation of mechanical compatibility of renders to apply on old walls based on a restrained shrinkage test. Materials and Structures. 2007; 40(10):1115-1126. http://dx.doi.org/10.1617/ s11527-006-9209-6

42. Balayssac JP, Nicot $\mathrm{P}$, Ruot $\mathrm{B}$, Devès $\mathrm{O}$ and Détriché $\mathrm{CH}$. Influence of admixtures on the cracking sensitivity of mortar layers applied to a mineral substrate. Construction and Building Materials. 2011; 25(6):2828-2836. http://dx.doi.org/10.1016/j. conbuildmat.2010.12.052

43. Veiga MR. Rules for awarding application documents to cement-based mineral binders' ready-mixed claddings for walls. Lisbon: LNEC; 2005. Report 427/05 - NRI. In Portuguese. 